\title{
Analisis Potensi dan Permasalahan Usaha Perikanan Budidaya di Kecamatan Bungursari Kota Tasikmalaya Provinsi Jawa Barat
}

\author{
[Potential and Problems Analysis of Aquaculture Business in Bungursari \\ District, Tasikmalaya City, West Java Province]
}

\section{Uidita Octaviola CST, lin Siti Djunaidah, Walson Halomoan Sinaga}

\author{
Jurusan Penyuluhan Perikanan, Sekolah Tinggi Perikanan \\ Jalan Cikaret No. 2, Bogor Selatan, Kota Bogor 16132
}

Diterima : 19 Februari 2019; Disetujui : 18 Maret 2019

\begin{abstract}
Abstrak
Kecamatan Bungursari memiliki $253.890 \mathrm{~m}^{2}$ lahan perikanan dan sumber air yang berasal dari sungai Cirombang dan Cidungkui. Terdapat 10 kelurahan yang mencangkup wilayah Kecamatan Bungursari. Dimana 4 kelurahan merupakan kelurahan potensial dibidang Perikanan. Salah satu kelurahannya adalah Kelurahan Cibunigeulis yang memiliki luas wilayah seluas $93.330 \mathrm{~m}^{2}$. Tujuan penelitian adalah mengidentifikasi potensi dan permasalahan usaha perikanan budidaya di Kecamatan Bungursari Kota Tasikmalaya Provinsi Jawa Barat. Hasil penelitian menunjukan bahwa mayoritas umur penduduk Kecamatan Bungursari usia 15-64 tahun sebanyak 67,1 \% yang termasuk dalam kategori usia produktif. Sebanyak $41 \%$ masyarakat Kecamatan Bungursari berpendidikan SMP. Terdapat $32 \%$ responden yang berpendidikan SD, $23 \%$ berpendidikan SMA, dan sangat sedikit yang berpendidikan sarjana yaitu $4 \%$. Tingkat pendapatan Responden di Kecamatan Bungursari rata-rata Rp. 2.538.042.bulan-1. Permasalahan yang terdapat adalah teknologi tradisional, belum ada lembaga penyedia SAPRAS, dan keuntungan masih rendah. Kondisi ini menunjukan bahwa perlu dilakukan identifikasi potensi wilayah untuk meningkatkan sosial ekonomi responden di Kecamatan Bungursari.
\end{abstract}

Kata kunci : sumber air, sumber daya alam, sumber daya manusia perikanan

\section{Abstract}

Bungursari District has $253.890 \mathrm{~m}^{2}$ of fishery land and water sources originating from the Cirombang river and Cidungkui. There are 10 villages that cover the district of Bungursari. Where 4 villages are potential villages in the fisheries sector. One of the villages is Kelurahan Cibunigeulis which has an area of $93.330 \mathrm{~m}^{2}$. The research objective is to identify the potential and problems of aquaculture business in the Bungursari District of Tasikmalaya City, West Java Province.The results showed that the majority of the population of Bungursari Subdistrict aged $15-64$ years as much as $67,1 \%$ were included in the productive age category. As many as $41 \%$ of the people of Bungursari Subdistrict have junior high school education. There are $32 \%$ of respondents who have elementary education, $23 \%$ have high school education, and very few have undergraduate education which is $4 \%$. Income level of Respondents in Bungursari Subdistrict on average Rp. 2.538.042. month $^{-1}$. The problem is traditional technology, there is no SAPRAS provider, and profits are still low. This condition shows that it is necessary to identify the potential of the region to improve the socio-economic respondents in the Bungursari District

Keywords: fisheries human resources, natural resources, water sources

Penulis Korespondensi

Uidita Octaviola CST | uidita14@gmail.com 


\section{PENDAHULUAN}

Jawa barat merupakan salah satu provinsi penghasil ikan budidaya air tawar yang memberikan konstribusi sebesar 597,531 ton terhadap produksi ikan air tawar nasional pada tahun 2016. Jawa Barat memiliki lokasi yang strategis yang dekat dengan ibukota hal ini memberikan kemudahan dalam hal akses teknologi dan pengembangan sumber daya melalui informasi dan pendidikan. Salah satu wilayah di Jawa Barat, Kota Tasikmalaya merupakan salah satu kota yang mempunyai potensi sektor perikanan yang cukup luas dengan pemanfaatan lahan untuk kolam budidaya seluas $621,23 \mathrm{Ha}$ dan $51,42 \mathrm{Ha}$ lahan mina padi (BPS 2016). Secara geografis Kota Tasikmalaya merupakan daerah perbukitan dengan ketersediaan sumber air untuk kegiatan budidaya relatif cukup sepanjang. Daerah ini berada pada ketinggian 201 hingga 503 mdpl.

Diantara 10 kecamatan di Kota Tasikmalaya, Kecamatan Bungursari merupakan sentral budidaya ikan yang memiliki lahan perikanan dalam sektor kolam budidaya sebesar 116,98 Ha dan 13,35 Ha sebagai lahan mina padi (BPS 2016). Oleh karna itu, perlu dilakukan kegiatan identifikasi potensi perikanan yang terdapat di wilayah tersebut dengan menggali data potensi sumber daya alam, sumber daya manusia, dan sumber daya penunjangnya. Penelitian bertujuan untuk mengidentifikasi potensi dan permasalahan usaha perikanan budidaya di Kecamatan Bungursari Kota Tasikmalaya Provinsi Jawa Barat.

\section{METODE PENELITIAN}

Metode yang digunakan dalam penelitian ini adalah metode studi kasus. Metode studi kasus adalah metode penelitian yang dilakukan dengan cara menjadikan objek penelitian sebagai suatu kasus yang perlu diteliti dan diAnalisis secara detail sampai tuntas. Satuan kasusnya adalah potensi dan permasalahan usaha perikanan di Kecamatan Bungursari.

\section{Waktu dan Lokasi penelitian}

Kegiatan penelitian ini dilakukan pada tanggal 1 November 2018 sampai dengan 30 November 2018. Lokasi penelitian bertempat di Kecamatan Bungursari, Kota Tasikmalaya, Provinsi Jawa Barat.

\section{Jenis dan Sumber data}

Jenis data yang dikumpulkan terbagi menjadi data primer dan data sekunder. Berdasarkan hasil pengamatan di lapangan data primer berupa data produksi budidaya, bisnis perikanan dan penyuluhan perikanan. Data sekunder berupa data register kelompok perikanan berupa jumlah 
kelompok, jumlah anggota, serta kelas kelompok, data kondisi wilayah perikanan Kota Tasikmalaya, Kecamatan Bungursari berupa profil, topografi, monografi dan jumlah penduduk.

Sumber untuk memperoleh data primer adalah secara langsung dari pelaku utama di lapangan. Sumber untuk memperoleh data sekunder berupa data tercatat diambil dari Kantor Dinas Pertanian dan Perikanan kota Tasikmalaya, Kantor Kecamatan Bungursari, studi kepustakaan atau literatur, internet.

\section{Teknik Pengumpulan Data}

Teknik pengumpulan data dalam penelitian melalui wawancara dan observasi langsung kepada responden dan melihat kondisi di lapangan. Alat yang digunakan untuk menggali data dalam kegiatan praktek ini adalah kuisioner dan borang sebagai acuan dalam pengambilan data. Jenis pertanyaan yang diberikan dalam kuesioner kepada responden bersifat terbuka dengan teknik wawancara. Selanjutnya hasil jawaban dari responden akan dipindah ke dalam borang yang telah disediakan.

\section{Metode Analisis Data}

Teknik pengambilan sampel yang digunakan adalah stratified random sampling (acak berlapis). Teknik acak berlapis ini dilaksanakan dengan melakukan random anggota populasi yang dikelompokkan menurut ciri-ciri tertentu. Ciri-ciri kelompok yang diambil sebagai sampel adalah memiliki kelompok terbanyak dan memiliki letak wilayah yang berdekatan.

Menurut Consuelo dan Sevilla (2007), cara menentukan besarannya ukuran sample memakai rumus slovin sebagai berikut :

$$
n=\frac{N}{1+N(e)^{2}}
$$

Ket :

$$
\begin{aligned}
& n=\text { ukuran sampel } \\
& \mathrm{N}=\text { Populasi } \\
& \mathrm{e}=\text { Tingkat kesalahan }(5 \%-20 \%) \\
& \mathrm{n}=\text { Jumlah Sampel }
\end{aligned}
$$

Berdasarkan

perhitungan Menggunakan slovin jumlah responden yang dijadikan sampel sebanayak 22 responden yang tersebar di 4 kelurahan yaitu kelurahan Cibunigeulis 15 responden, Sukarindik sebanyak 3 responden, Sukajaya sebanyak 2 responden, dan Bantarsari sebanyak 2 responden.

Metode analisis data deskriptif yang digunakan dalam praktek keahlian dapat menggunakan Tree Analysis. Analisis pohon kesalahan (Fault Tree Analysis) merupakan salah satu metode yang dapat digunakan untuk mencari akar penyebab masalah dari macammacam permasalahan yang ada 
(Anthony dan Noya 2015). Fault Tree

Analysis secara umum adalah suatu teknik yang digunakan untuk mengidentifikasi resiko yang mempengaruhi terjadinya kegagalan. Metode ini dilakukan dengan pendekatan terhadap kondisi yang tidak dikehendaki, yang diawali dengan asumsi kegagalan atau kerugian dari kejadian yang diinginkan kemudian merinci sebabsebab suatu Top Event sampai pada suatu kegagalan dasar.

\section{HASIL DAN PEMBAHASAN}

\section{Gambaran Umum Kecamatan Bungursari}

Kecamatan Bungursari (Gambar 1) merupakan salah satu kecamatan yang berada di Kota Tasikmalaya. Kecamatan ini merupakan hasil pemekaran dari Kecamatan Indihiang pada tahun 2008 mempunyai luas wilayah $16,91 \mathrm{~km}^{2}$ meliputi 7 kelurahan yaitu kelurahan Bungursari, Bantarsari, Cibunigeulis, Sukalaksana, Sukamulya, Sukajaya, dan Sukarindik.

Kecamatan Bungursari memiliki ketersediaan lahan perikanan seluas $253.890 \mathrm{~m}^{2}$ dan Sumber air yang berasal dari sungai Cirombang dan Cidungkui yang mampu mengaliri kolam-kolam di Kecamatan Bungursari. Selain itu kecamatan Bungursari terletak dibawah kaki Gunung Galunggung yang merupakan gunung terbesar yang ada di kota Tasikmalaya. Kelurahan Cibunigeulis merupakan wilayah yang memiliki lahan perikanan terbesar dengan luas $93.300 \mathrm{~m}^{2}$ dan kelurahan Sukamulya merupakan yang terkecil memiliki lahan perikanan dengan luas $11.000 \mathrm{~m}^{2}$.

Menurut (Firdaus 2009), sumber daya manusia adalah suatu prosedur

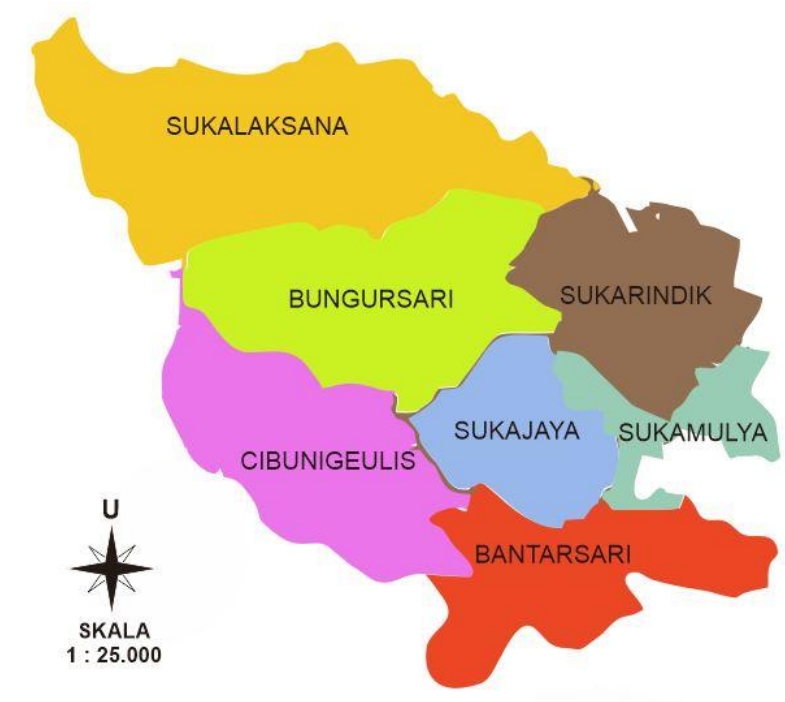

Gambar 1. Peta Kecamatan Bungursari Kota Tasikmalaya 
Tabel 1. Jumlah dan Tingkat Kemampuan Kelompok di Kecamatan Bungursari

\begin{tabular}{llccc}
\hline \multirow{2}{*}{ No } & \multicolumn{1}{c}{ Kelurahan } & \multicolumn{3}{c}{ Kelas Kelompok Perikanan } \\
\cline { 3 - 5 } & & Pemula & Madya & Jumlah \\
\hline 1. & Cibunigeulis & 5 & 3 & 11 \\
2. & Sukajaya & 5 & - & 5 \\
3 & Sukarindik & 5 & - & 5 \\
4 & Bantarsari & 10 & - & 10 \\
5 & Sukalaksana & 4 & 1 & 5 \\
6 & Sukamulya & 2 & 1 & 3 \\
7 & Bungursari & 4 & - & 4 \\
Jumlah & 38 & 5 & 43 \\
\hline
\end{tabular}

yang berkelanjutan yang bertujuan untuk memasok suatu organisasi atau perusahaan dengan orang-orang yang tepat untuk ditempatkan pada posisi dan jabatan yang tepat pada suatu organisasi. Dilihat dari potensi sumberdaya manusia, Kecamatan Bungursari mempunyai jumlah penduduk sebanyak 47.938 jiwa. Dengan jumlah penduduk laki-laki sebanyak 24.502 jiwa dan jumlah penduduk perempuan yaitu 23.436 jiwa. Berdasarkan usia, penduduk yang berusia 0 -14 tahun sebanyak 26,6 \%, usia 15-64 tahun sebanyak $67,1 \%$ dan usia 65 tahun keatas sebanyak 6,3\%. Menurut (BPS 2018), usia 15 - 64 tahun merupakan usia produktif dimana peluang untuk terciptanya Sumber Daya Manusia (SDM) yang merupakan pasar potensial untuk memasarkan hasil produksi. Peningkatan pengetahuan penduduk salah satunya dapat ditingkatkan melalui jenjang pendidikan sehingga hal ini dapat dianggap mempengaruhi pengetahuan, sikap, dan keterampilan yang dimiliki. Tingkat pendidikan tertinggi yaitu SD sebanyak 17.231 jiwa atau 35,9 \% dari keseluruhan jumlah penduduk berdasarkan tingkat pendidikan.

\section{Keragaan Usaha Perikanan}

Kecamatan

Bungursari mempunyai potensi perikanan yang baik, dimana kecamatan Bungursari memiliki 43 kelompok perikanan budidaya (Tabel 1). Setiap kelurahan memiliki jumlah kelompok yang berbeda, kelurahan Cibunigeulis memiliki 11 POKDAKAN, Kelurahan Sukarindik memiliki 5 Pokdakan, kelurahan Bantarsari memiliki 10 POKDAKAN, dan kelurahan Sukajaya memiliki 5 POKDAKAN. Karakteristik kelompok perikanan di kecamatan Bungursari ditinjau dari kelas kemampuannya dapat digolongkan 
menjadi 2 kelas, yaitu : Pemula dan Madya. Menurut Hariadi (2011), kelompok tani dapat diklasifikasikan sebagai kelas pemula, kelas lanjut, kelas madya, dan kelas utama. Namun, berbeda dengan kelompok tani, kriteria kemampuan kelompok di perikanan berdasarkan PP No 622014 hanya dibedakan dengan tiga kelas saja, yakni kelompok kelas pemula, madya, dan utama. Kelas kemampuan kelompok ini dinilai dari kebijakan atau kegiatan yang ada dalam kelompok.

Kecamatan Bungursari memiliki 43 kelompok perikanan dimana terdapat 38 kelompok kelas Pemula dengan skor rata-rata 302,1; 5 kelompok kelas Madya dengan skor rata-rata 387,75; dan belum terdapat kelompok kelas Utama. Kelurahan Cibunigeulis memiliki jumlah kelompok terbanyak yaitu 11 kelompok dan Kelurahan Sukamulya memiliki jumlah terkecil dengan jumlah kelompok perikanan sebanyak 3 kelompok. Pada kelurahan Cibunikeulis terdapat 2 kelompok yang memiliki kelas kemampuan madya dengan Skor ratarata 387,75. Sedangkan 29 kelompok lainnya memiliki kelas kelompok pemula dengan skor 302,1.

\section{Karakteristik Sosial Ekonomi Responden}

Karakteristik Sosial Responden

Karakteristik sosial responden meliputi pendidikan, usia, dan lama usaha. Menurut Mardikanto (2009), pendidikan petani pada umumnya mempengaruhi cara dan pola pikir petani dalam mengelola usaha taninya, semakin tinggi tinggi tingkat pendidikan seseorang, semakin tinggi efisien

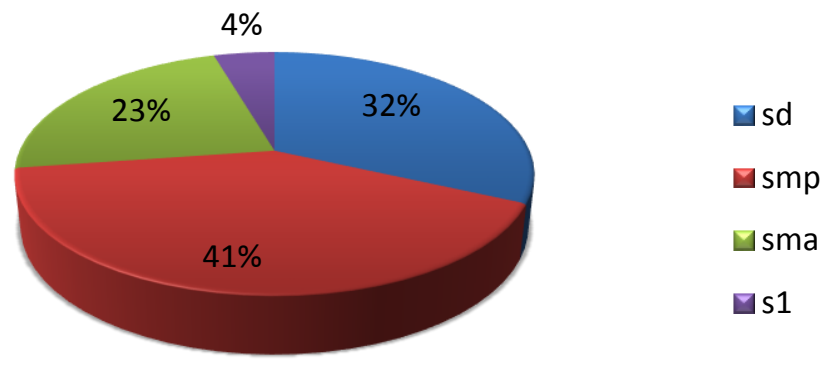

Gambar 2. Persentase Pendidikan di Kecamatan Bungursari.

Tabel 2. Umur Responden

\begin{tabular}{ccccc}
\hline Umur & $\mathbf{3 0 - 4 0}$ & $\mathbf{4 1 - 5 0}$ & $\mathbf{5 1 - 6 0}$ & $\mathbf{6 1 - 7 0}$ \\
\hline Jumlah Responden & 2 & 3 & 13 & 4 \\
\hline
\end{tabular}


bekerja dan semakin banyak menyadari cara bertani lebih baik dan menguntungkan. Pendidikan responden dikecamatan Bungursari sangat beragam dari SD hingga sarjana (Gambar 2). Dengan mayoritas (41\%) berpendidikan SMP. Terdapat $32 \%$ responden yang berpendidikan SD, $23 \%$ berpendidikan SMA, dan sangat sedikit yang berpendidikan sarjana yaitu $4 \%$. Sebagaimana yang disampaikan (Rakhmanda, Suadi, dan Djasmani 2018), bahwa tingkat pendidikan ini sangat mempengaruhi pelaku utama terkadang kesulitan untuk menerima pengetahuan-pengetahuan bari karena rendahnya pendidikan formal yang mereka terima.

Berdasarkan usia, responden dikecamatan Bungursari rata-rata berusia 15 - 64 tahun (Tabel 2). Lama kegiatan usaha perikanan yang dilakukan responden dapat dilihat pada Tabel 3. Kelompok Ligar jaya merupakan kelompok usaha perikanan yang sudah lama berjalan yaitu dari tahun 2007. Dan diikuti oleh kelompok usaha Harapan Warga dan Mukti Jaya yang berdiri pada tahun 2009. Lama usaha seorang pelaku bisnis dengan menekuni bidang usahanya akan mempengaruhi produktivitasnya

(kemampuan

Tabel 3. Usaha Perikanan Budidaya di Kecamatan Bungursari

\begin{tabular}{|c|c|c|c|c|c|}
\hline No & Kelurahan & Nama Kelompok & $\begin{array}{l}\text { Tahun } \\
\text { Berdiri }\end{array}$ & $\begin{array}{c}\text { Jumlah } \\
\text { Anggota }\end{array}$ & Komoditas \\
\hline 1 & Sukarindik & Patin Jaya & 2014 & 10 & Patin \\
\hline 2 & sukaninaik & Arimbi Putra & 2017 & 12 & Lele, Gurame \\
\hline 3 & Cukoiny & Al Waton & 2012 & 10 & Nila \\
\hline 4 & sukajaya & Harapan Warga & 2009 & 10 & Mas \\
\hline 5 & & Guras & 2012 & 15 & Gurame \\
\hline 6 & & Mukti Jaya & 2009 & 14 & Mas, Nila, Nilem, \\
\hline 7 & & Ligar Jaya & 2007 & 12 & Gurame, Nila \\
\hline 8 & & Bina Karya & 2011 & 10 & Nilem, Mas, Nila \\
\hline 9 & Cibunigeulis & Nangela & 2012 & 12 & Gurame \\
\hline 10 & & Gurilem & 2011 & 10 & Gurame, Nilem \\
\hline 11 & & Mina Hurip & 2016 & 12 & Nila \\
\hline 12 & & $\begin{array}{l}\text { Mina Gunung } \\
\text { Kokosan }\end{array}$ & 2016 & 11 & Nilem, Mas, Gurame \\
\hline 13 & & Mekar Jaya & 2017 & 11 & $\begin{array}{l}\text { Nilem, Nila, Mas, } \\
\text { Gurame }\end{array}$ \\
\hline 14 & Bantarsari & Mina Guci & 2015 & 10 & Nila, Mas \\
\hline
\end{tabular}


profesionalnya/ keahlianya),/ semakin lama menekuni bidang usahanya, akan semakin meningkat pengetahuan tentang selera ataupun perilaku konsumen (Wicaksono dan Purwanti 2010).

Hasil dari perhitungan penetapan sample yang telah dilakukan maka didapatkan 22 Responden dari 4 Kelurahan yang diidentifikasi terdapat 14
POKDAKAN yang aktif dalam usaha perikanan (Tabel 3). Menurut Walangdi dalam Zubair dan Yasin (2011), usaha perikanan dapat dipandang sebagai suatu perpaduan faktor produksi atau suatu barang antara yang dihasilkan faktor-faktor produksi klasik tenaga kerja dan barang-barang modal atau apapun yang dianggap sejenisnya.

Tabel 4. Produksi dan Produktivitas Pembesaran Ikan Nila

\begin{tabular}{|c|c|c|c|c|c|c|c|c|}
\hline \multirow[b]{2}{*}{$\begin{array}{l}\text { Responden } \\
\text { No }\end{array}$} & \multirow[b]{2}{*}{$\begin{array}{l}\text { Luas } \\
\text { Wadah } \\
\text { (m2) }\end{array}$} & \multicolumn{2}{|c|}{ Penebaran Benih } & \multicolumn{2}{|c|}{ Panen } & \multirow[b]{2}{*}{$\begin{array}{c}\text { Total } \\
\text { Produksi } \\
(\mathbf{k g})\end{array}$} & \multirow[b]{2}{*}{$\begin{array}{l}\text { Produktivitas } \\
\quad\left(\mathbf{k g} \cdot \mathrm{m}^{-2}\right)\end{array}$} & \multirow[b]{2}{*}{$\begin{array}{l}\text { SR } \\
(\%)\end{array}$} \\
\hline & & $\begin{array}{c}\text { Jumlah } \\
\text { (ekor) }\end{array}$ & $\begin{array}{c}\text { Padat } \\
\text { Tebar } \\
(\text { ekor.m-2) }\end{array}$ & $\begin{array}{l}\text { Bobot } \\
\text { (g) }\end{array}$ & $\begin{array}{c}\text { Jumlah } \\
\text { (ekor) }\end{array}$ & & & \\
\hline 1 & 2520 & 5000 & 1,984127 & 200 & 4900 & 980 & 0,39 & 98 \\
\hline 2 & 1190 & 2500 & 2,10084 & 200 & 2450 & 490 & 0,41 & 98 \\
\hline 3 & 1288 & 8928 & 6,931677 & 200 & 8749 & 1749,8 & 1,36 & 98 \\
\hline 4 & 1568 & 7840 & 5 & 100 & 7683 & 768,3 & 0,49 & 98 \\
\hline 5 & 1400 & 165000 & 117,8571 & 200 & 14000 & 2800 & 2,00 & 8 \\
\hline 6 & 574 & 7000 & 12,19512 & 300 & 600 & 180 & 0,31 & 9 \\
\hline 7 & 294 & 2500 & 8,503401 & 250 & 400 & 100 & 0,34 & 16 \\
\hline 8 & 980 & 70000 & 71,42857 & 13 & 28000 & 364 & 0,37 & 40 \\
\hline 9 & 1050 & 100000 & 95,2381 & 13 & 12000 & 156 & 0,15 & 12 \\
\hline 10 & 1400 & 5250 & 3,75 & 66 & 4500 & 297 & 0,21 & 86 \\
\hline 11 & 770 & 9000 & 11,68831 & 125 & 6400 & 800 & 1,04 & 71 \\
\hline Rata-rata & & & 30,60703 & & & & 0,64 & $48,70 \%$ \\
\hline
\end{tabular}

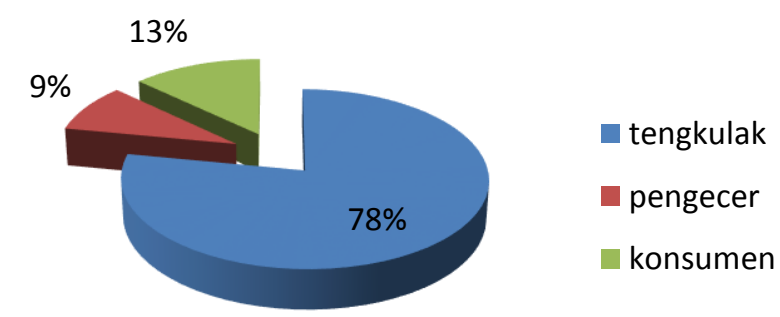

Gambar 3. Persentase Saluran Pemasaran 
Karakteristik Ekonomi Responden

Karakteristik ekonomi responden meliputi produksi dan produktivitas, pemasaran dan Analisis usaha. Usaha perikanan yang terdapat di Kelurahan sampel di Kecamatan Bungursari yaitu budidaya ikan air tawar (pembesaran dan pembenihan) nila, patin, mas, nilem, dan lele (Tabel 2).Produksi Benih ikan lele di kecamatan Bungursari dan jumlah RTP pembesaran ikan Nila dapat dilihat pada Tabel 4.

Padat tebar rata-rata 31 ekor.m-2 dalam kegiatan pembesaran ikan nila belum sesuai ketetapan produksi ikan nila kelas pembesaran di kolam air tenang SNI : 7550.2009 yang menyatakan padat tebar Nila kelas pembesaran hanya berkisar 5-7 ekor. $\mathrm{m}^{-2}$ (BSN 2009). SR rata-rata di Kecamatan Bungursari adalah $48,7 \%$, hasil tersebut digolongkan rendah karena menurut penelitian (Marie, Syukron, dan Rahardjo 2018), tingkat kelangsungan hidup Ikan Nila yang tinggi dapat mencapai $90-95 \%$ dikarenakan kolam budidaya terbuat dari beton. Produksi rata-rata responden dikecamatan Bungursari adalah 723,8 kg.siklus ${ }^{-1}$, dengan produktivitas 0,64 $\mathrm{kg} \cdot \mathrm{m}^{-2}$.

Alur pemasaran pembenihan dan pembesaran yang ada di Kecamatan Bungursari, dapat dilihat pada Gambar 3. Sebanyak $78 \%$ pembudidaya ikan dipasarkan ke tengkulak, ke pengecer sebanyak 9\% dan ke konsumen langsung sebanyak 13\%. Sebagaimana dinyatakan (Mahyudin 2008), bahwa pemasaran secara tidak langsung yaitu semakin jauh jaraknya semakin panjang tata niaga yang harus dilalui.

Analisis usaha pembesaran ikan Nila ketua kelompok Ligar Jaya di kelurahan Cibunigeulis Kecamatan Bungursari dengan luas wadah seluruhnya $1.568 \mathrm{~m}^{2}$ terbagi dengan 3 petak kolam.

a. Biaya Produksi

Total Biaya Produksi = Biaya Tetap

+ Biaya Variabel

$=478.750+4.944 .000$

$=\mathbf{5 . 4 2 2 . 7 5 0}$

b. Penerimaan

Dari jumlah benih yang ditebar pembudidaya yaitu sebanyak 7.840 ekor, setelah masa pemeliharaan selama 3 bulan tingkat kehidupan 98\% dan menghasilkan ikan yang dipanen mencapai 7.683 ekor atau 768,3 kg dengan harga jual ikan Nila mencapai Rp $20.000 \mathrm{~kg}^{-1}$.

Penerimaan yang diperoleh $=R p$ $20.000 \mathrm{~kg}^{-1} \times 768,3 \mathrm{~kg}=\mathbf{R p}$ 15.366.000

c. Keuntungan

Keuntungan usaha yang diperoleh kelompok pembudidaya di Kecamatan Bungursari dari usaha 
pembesaran ikan lele adalah sebagai berikut :

Keuntungan usaha

Penerimaan - Total Biaya Produksi

$=$ Rp. $15.366 .000-$ Rp 5.422.750

$=\operatorname{Rp} 9.943 .250$

d. Revenue Cost Ratio (R/C)

Perhitungan ini lebih ditekankan pada kriteria-kriteria investasi yang pengukurannya di arahkan pada usaha untuk memperbandingkan, mengukur, serta menghitung tingkat keuntungan usaha perikanan. Dengan $\mathrm{R} / \mathrm{C}$ ini bisa dilihat kelayakan suatu usaha.

$$
\begin{gathered}
\frac{R}{C}=\frac{\text { Penerimaan }}{\text { Total Biaya Produksi }} \\
=\frac{\text { Rp. } 15 \cdot 366 \cdot 000}{\text { Rp. } 5 \cdot 422 \cdot 750} \\
=2,8
\end{gathered}
$$

Nilai $\mathrm{R} / \mathrm{C}$ sebesar 2,8 menunjukkan bahwa usaha pembesaran ikan Nila milik Uum layak diteruskan. Karena suatu usaha dapat dikatakan layak untuk dikembangkan apabila nilai $\mathrm{R} / \mathrm{C}$ dari usaha tersebut diatas 1 .

e. Break Even Point (BEP)

Break event point merupakan perhitungan untuk mengetahui pada jumlah penjualan ikan nila yang akan terjadi titik impas maksudnya hasil penjualan produksi sama dengan biaya produksi sehingga pengeluaran sama dengan pendapatan. BEP ini digunakan untuk menentukan batas minimum volume penjualan agar suatu perusahaan tidak rugi. Diteruskan usaha serta produksi.

$$
\begin{gathered}
\text { BEP }(\text { Rupiah })=\frac{\text { Biaya Tetap }}{1-\frac{\text { Biaya Variabel }}{\text { Penerimaan }}} \\
\text { BEP }(\text { Rupiah })=\frac{\text { Rp.478.750 }}{1-\frac{4.944 .000}{15.366 .000}} \\
\text { BEP (Rupiah) }=\text { Rp.704.044 }
\end{gathered}
$$

$$
\begin{gathered}
\text { BEP (Unit) }=\frac{\text { Biaya Tetap }}{\frac{\text { Penjualan }}{\text { Unit }}-\frac{\text { Biaya Variabel }}{\text { Unit }}} \\
\text { BEP (Unit) }=\frac{478.750}{\text { Rp.20.000-Rp.6.434 }} \\
\text { BEP (Unit) }=35,2 \mathrm{~kg}
\end{gathered}
$$

\section{f. Payback Period (PP)}

Penilaian usaha menggunakan metode ini didasarkan pada lamanya investasi tersebut dapat tertutup dengan aliran-aliran kas masuk.

$$
\begin{gathered}
\mathrm{PP}=\frac{\text { Investigasi }}{\text { Laba }} \times \text { Periode Produksi } \\
\mathrm{PP}=\frac{\mathrm{Rp} \cdot 157.300 .000}{\mathrm{Rp} .9 .943 .250(4)} \\
\mathrm{PP}=3,9 \text { tahun }
\end{gathered}
$$

Berdasarkan perhitungan hasil yang didapat adalah 3,9 tahun yang artinya untuk mengembalikan modal investasi memerlukan waktu 3,9 tahun. Dalam menganalisis perbandingan pendapatan 
Tabel 5. Masalah Umum dan Masalah Khusus Di Kecamatan Bungursari.

\begin{tabular}{|c|c|}
\hline Masalah Umum & Masalah Khusus \\
\hline Teknologi Tradisional & $\begin{array}{l}\text { 1. Pembudiaya belum mempersiapkan kolam secara } \\
\text { optimal. } \\
\text { 2. Pembudidaya belum mengetahui padat tebar ikan } \\
\text { yang sesuai SNI } \\
\text { 3. Pembudidaya mengandalkan pakan alami. }\end{array}$ \\
\hline $\begin{array}{l}\text { Belum adanya lembaga penyedia } \\
\text { SAPRAS khusus perikanan. }\end{array}$ & $\begin{array}{l}\text { 4. Belum adanya koprasi penyedia pakan khusus ikan. } \\
\text { 5. Belum adanya penyedia pupuk dan kapur khusus } \\
\text { perikanan }\end{array}$ \\
\hline Keuntungan Usaha Rendah & $\begin{array}{l}\text { 6. Kurangnya pengetahuan tentang sistem pemasaran. } \\
\text { 7. Kurangnya pemahaman pembudidaya tentang } \\
\text { pentingnya berkelompok. } \\
\text { 8. Kurangnya koordinasi antar anggota kelompok } \\
\text { sehingga pengembangan kelompok tidak meluas. } \\
\text { 9. Belum adanya soialisasi tentang tugas pokok dan } \\
\text { fungsi anggota kelompok }\end{array}$ \\
\hline
\end{tabular}

pembudidaya dengan UMR, ratarata pendapatan pembudidaya di kecamatan Bungursari adalah $\mathrm{Rp}$ 2.538.042, yang mana lebih besar dari UMR yang hanya $\mathrm{Rp} 2.086 .000$.

\section{Analisis Permasalahan}

Berdasarkan hasil dari perumusan kondisi di Kecamatan Bungursari Kota Tasikmalaya, maka diperoleh hasil berupa 3 masalah umum yaitu teknologi yang digunakan bersifat sederhana, belum tersedianya lembaga penyedia Sapras dan keuntungan usaha rendah (Tabel 5).

Dari segi teknologi terdapat 4 masalah khusus antara lain; 1) responden belum menerapkan persiapan kolam secara optimal, 2) belum mengetahui padat tebat sesuai dengan
SNI, 3) mengandalkan pakan alami dan limbah, 4) belum adanya lembaga penyedia pakan. dan dari segi keuntungan ada 4 masalah khusus yaitu kurangnya pengetahuan mengenai sistem pemasaran, pemahaman responden terhadap pentingnya berkelompok, dan kurangnya koordinasi antar sesama anggota kelompok sehingga pengembangan pemasaran kurang meluas. Serta belum adanya lembaga penyedia saran dan prasarana khusus dibidang perikanan. $\mathrm{Hal}$ ini menjadi permasalah usaha dibidang perikanan yang dihadapi responden di Kecamatan Bungursari Kota Tasikmalaya Provinsi Jawa Barat. 


\section{SIMPULAN DAN SARAN}

\section{Kesimpulan}

Berdasarkan hasil Analisis data secara primer dan sekunder serta identifikasi permasalahkan disimpulkan kondisi wilayah potensial perikanan di Kecamatan Bungursari meliputi sumber daya alam, sumber daya manusia dan sumber daya penunjang. Potensi sumber daya alam terdiri dari: Luas Iahan perikanan seluas $253.890 \mathrm{~m}^{2}$, sumber air berasal dari sungai Cigombong dan Cirombang dan daerah potensi perikanan tersebar tersebar 4 Kelurahan yaitu kelurahan Cibunigeulis, kelurahan Sukarindik, kelurahan Sukajaya, dan kelurahan Bantarsari. Potensi sumber daya manusia meliputi : a) Jumlah penduduk 47.938 jiwa, dengan jumlah RTP 461 , b) Kelompok yang ada berjumlah 43 kelompok pembudidaya. dan c) Sistem produksi perikanan masih bersifat tradisional.

Permasalahan yang ditemukan dari hasil pengolahan data diantaranya, teknologi yang digunakan masih tradisional, pemberian pakan belum intensif, dan keuntungan usaha masih rendah. Disebabkan oleh belum ada sosialisasi tentang penerapan persiapan kolam oleh penyuluh, belum tersedianya koperasi yang menyediakan SAPRAS khusus perikanan, dan kurangnya pengetahuan tentang sistem pemasaran.

\section{Saran}

Berdasarkan kesimpulan diatas, maka penulisan menyarankan hal-hal sebagai berikut: Kecamatan Bungursari memiliki potensi yang cukup bagus, maka perlu dilakukan pengembangan penerapan teknologi pengelolaan sumber daya alam yang berkelanjutan dan terpadu sehingga dapat meningkatkan kesejahteraan masyrakat. Perlu dukungan dari pemerintah setempat khususnya Dinas Perikanan untuk membantu kegiatan kelompok seperti pengadaan sarana dan prasarana. Adapun penambahan dalam jumlah penyuluh perikanan agar program yang telah disusun dapat berjalan sesuai dengan rencana yang telah ditetapkan.

\section{DAFTAR PUSTAKA}

Anthony, Roberto dan Sunday Noya. 2015. "The Application of Hazard Identification and Risk Analysis (HIRA) and Fault Tree Analysis (FTA) Methods for Controling Occupational Accidents in Mixing Division Dewa-Dewi Farm." Jurnal IImiah Teknik Industri 3(2).

BPS. 2016. "Luas Area Tempat Pemeliharaan Ikan di Kota Tasikmalaya 2015."

BPS. 2018. "Produksi Perikanan Budidaya menurut Kabupaten/Kota Subsektor di Jawa Barat 2016." 
BSN. 2009. "SNI 7550:2009 tentang Produksi Ikan Nila (Oreochromis niloticus Bleeker) Kelas Pembesaran di Kolam Air Tenang." Consuelo, G. dan Ed D. Sevilla. 2007. "Research methods." Revised Edition (Manila: Rex Bookstore, 1992) 94.

Firdaus, Muhammad. 2009. Manajemen Agribisnis. Bumi Aksara.

Hariadi, Sunarru Samsi. 2011. Dinamika kelompok: teori dan aplikasinya untuk analisis keberhasilan kelompok tani sebagai unit belajar, kerjasama, produksi, dan bisnis. Sekolah Pascasarjana, Universitas Gadjah Mada.

Mahyudin. 2008. Kebutuhan Karbohidrat Pakan untuk Ikan Bandeng. Medan (ID): Universitas Sumatera Utara.

Mardikanto, Totok. 2009. Sistem penyuluhan pertanian. Surakarta (ID): UNS Press.

Marie, Roose, Mochammad Ali Syukron, dan Seto Sugianto Prabowo Rahardjo. 2018. "Teknik Pembesaran Ikan Nila (Oreochromis niloticus) dengan Pemberian Pakan Limbah Roti." Jurnal Sumber Daya Alam dan Lingkungan 5(1).

PP No 62. 2014. Peraturan Pemerintah tentang Penyelenggaraan
Pendidikan, Pelatihan, dan Penyuluhan. Indonesia.

Rakhmanda, Andhika, Suadi, dan Supardjo Supardi Djasmani. 2018. "Peran Kelompok Nelayan dalam Pekembangan Perikanan di Pantai Sadeng Kabupaten Gunung Kidul." Sodality Jurnal Sosiologi Pedesaan 6(2):94-104.

Wicaksono, Rezal dan Evi Yulia Purwanti. 2010. "Analisis Pengaruh PDB Sektor Industri, Upah Riil, Suku Bunga Riil, dan Jumlah Unit Usaha Terhadap Penyerapan Tenaga Kerja pada Industri Pengolahan Sedang dan Besar di Indonesia Tahun 1990-2008 [Skripsi]." Universitas Diponegoro. Zubair, Sofyan dan Muhammad Yasin. 2011. "Analisis Pendapatan Nelayan Pada Unit Alat Tangkap Payang Di Desa Pabbaressang Kec. Bua Kab. Luwu [Skripsi]." Universitas Hasanudin. 
